\title{
A Stable Single-Site Palladium Catalyst for Hydrogenations
}

\author{
Gianvito Vilé, Davide Albani, Maarten Nachtegaal, Zupeng Chen, Dariya Dontsova, \\ Markus Antonietti, Núria López, * and Javier Pérez-Ramírez*
}

\begin{abstract}
We report the preparation and hydrogenation performance of a single-site palladium catalyst that was obtained by the anchoring of Pd atoms into the cavities of mesoporous polymeric graphitic carbon nitride. The characterization of the material confirmed the atomic dispersion of the palladium phase throughout the sample. The catalyst was applied for three-phase hydrogenations of alkynes and nitroarenes in a continuous-flow reactor, showing its high activity and product selectivity in comparison with benchmark catalysts based on nanoparticles. Density functional theory calculations provided fundamental insights into the material structure and attributed the high catalyst activity and selectivity to the facile hydrogen activation and hydrocarbon adsorption on atomically dispersed $\mathrm{Pd}$ sites.
\end{abstract}

The selective hydrogenation of acetylenic and nitroaromatic compounds is an important step in the synthesis of building blocks for polymers, vitamins, fragrances, and agrochemicals. ${ }^{[1]}$ Commercial catalysts for this family of reactions are based on supported Pd or Pt nanoparticles modified with harmful promoters such as lead (Lindlar) or, more recently, with organic ligands (NanoSelect). ${ }^{[2]}$ The modifiers not only alter the adsorption energies of the reactants and products but also reduce the size of the ensemble of surface atoms where the reaction takes place. This prevents oligomer production and hydride formation, the latter being responsible for the undesired isomerization and over-hydrogenation pathways. ${ }^{[2]}$ In attempts to improve the performance of conventional catalysts, enormous efforts have been devoted to the design of materials with tailored metal-particle sizes. ${ }^{[3]}$ In fact, engineering a minimal ensemble that is able to activate $\mathrm{H}_{2}$ and displays interactions that are strong enough with the reactants and weak with the products would offer unrivalled oppor-

[*] G. Vilé, ${ }^{[+]}$D. Albani, ${ }^{[+]}$Prof. J. Pérez-Ramírez

Institute for Chemical and Bioengineering

Department of Chemistry and Applied Biosciences, ETH Zurich

Vladimir-Prelog-Weg 1, 8093 Zurich (Switzerland)

E-mail: jpr@chem.ethz.ch

Dr. M. Nachtegaal

Paul Scherrer Institute, 5232 Villigen (Switzerland)

Z. Chen, Dr. D. Dontsova, Prof. M. Antonietti

Max-Planck Institute of Colloids and Interfaces

Department of Colloid Chemistry

Research Campus Golm, 14424 Potsdam (Germany)

Prof. N. López

Institute of Chemical Research of Catalonia (ICIQ)

Av. Països Catalans 16, 43007 Tarragona (Spain)

E-mail:nlopez@iciq.es

$\left[{ }^{+}\right]$These authors contributed equally to this work.

D)

Supporting information for this article is available on the WWWW under http://dx.doi.org/10.1002/anie.201505073. tunities for atom-efficient catalytic transformations. The ultimate frontier in size reduction is a single-site heterogeneous catalyst, in which isolated metal atoms anchored on a support catalyze hydrogenation reactions, mimicking the activity of biological entities such as enzymes and antibodies. $^{[4]}$ Flytzani-Stephanopoulos and co-workers have recently demonstrated that a single crystal containing a $\mathrm{Cu}(111)$ surface doped with isolated $\mathrm{Pd}$ atoms can activate hydrogen and display activity in the hydrogenation of acetylene under ultra-high vacuum conditions. ${ }^{[5 a]}$ Nevertheless, the relatively low ethylene selectivity ( $30 \%)$ at moderate acetylene conversions (10-20\%) and the pressure and material gaps of the model catalyst limit the broad applicability of this work. The synthesis of more realistic single-site heterogeneous catalysts remains to be a challenging task as isolated atoms are often thermodynamically unstable and tend to leach and agglomerate during the first few hours of a reaction. ${ }^{[5 b-e]}$ To design stable single-site catalysts, it is crucial to select a high-surface-area support containing "cages" or "cavities" that can entrap the catalytically active atoms in an isolated form, similarly to what has been done in the past for asymmetric organometallic catalysts and "ship-ina-bottle" nanostructures. ${ }^{[4]}$

Mesoporous polymeric graphitic carbon nitride (mpg$\mathrm{C}_{3} \mathrm{~N}_{4}$ ) has attracted increasing interest in the field of material science owing to its lattice-hole structure that partially resembles a Sierpińsky sieve. The material, in fact, contains characteristic N-coordinating cavities formed during the polymerization of heptazine, which are called "six-fold cavities" as they are delimited by six $\mathrm{C}_{3} \mathrm{~N}_{4}$ rings (see Figure $1 \mathrm{a}$; see also the Supporting Information, Figure S1). ${ }^{[6]}$ This structure gives rise to unique mechanical, electronic, and conducting properties that are not encountered in bulk carbon nitride samples. ${ }^{[7]}$ Using this material, we were able to strongly anchor isolated Pd species into host cavities, designing the first stable single-site heterogeneous catalyst for hydrogenations (hereafter referred to as $[\mathrm{Pd}] \mathrm{mpg}-\mathrm{C}_{3} \mathrm{~N}_{4}$; for details on its preparation, see the Supporting Information). A combination of characterization studies, catalytic tests in a continuous-flow reactor, and density functional theory (DFT) calculations led to a molecular-level understanding of the structure and reactivity of this novel material.

The [Pd]mpg- $\mathrm{C}_{3} \mathrm{~N}_{4}$ sample contains $0.5 \mathrm{wt} \%$ Pd (Table 1). The mpg- $\mathrm{C}_{3} \mathrm{~N}_{4}$ carrier has a total surface area of $155 \mathrm{~m}^{2} \mathrm{~g}^{-1}$ and a total pore volume of $0.26 \mathrm{~cm}^{3} \mathrm{~g}^{-1}$. Microscopic examination (Figure 1a) revealed that the palladium phase was atomically distributed throughout the sample (metal dispersion: $100 \%$ ). This was confirmed by an analysis of the metal distribution, displaying an average particle size of approximately $0.3-0.4 \mathrm{~nm}$, which matches the van der Waals diameter of a single palladium atom. X-ray absorption fine- 
(a)

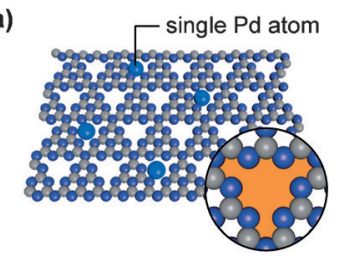

(b)

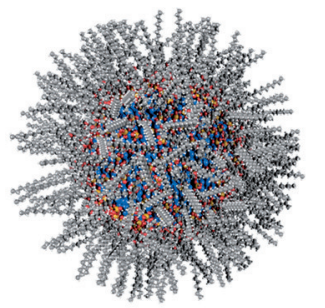

(c)

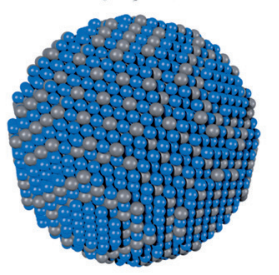

(d)

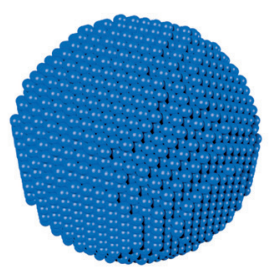

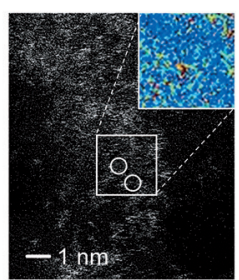
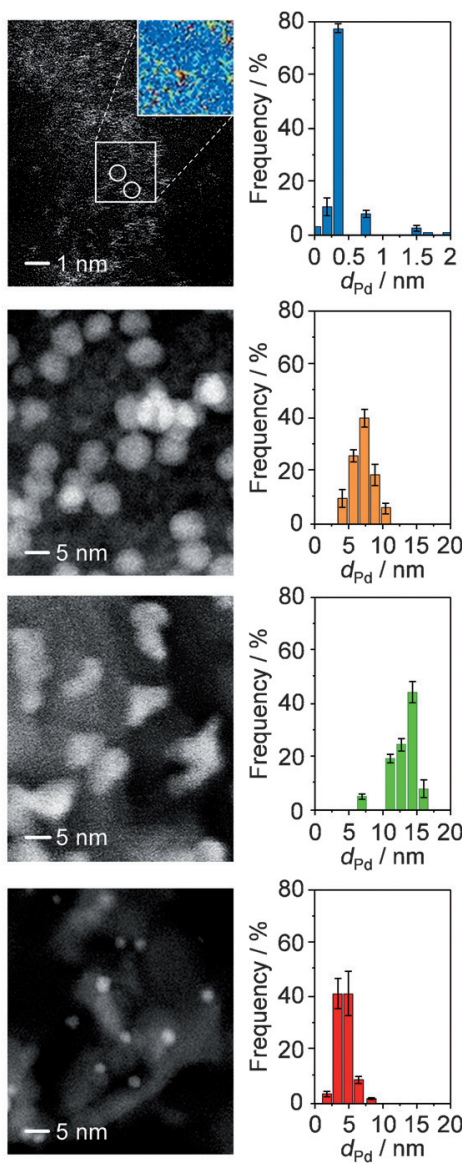

(a)

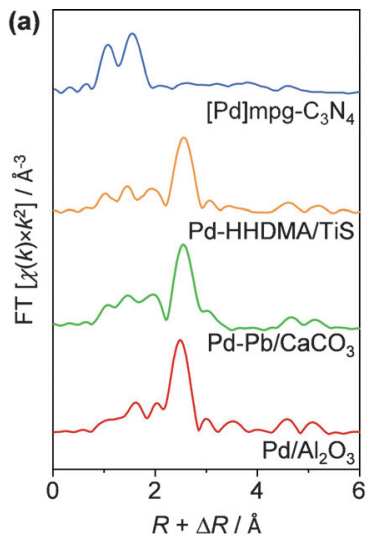

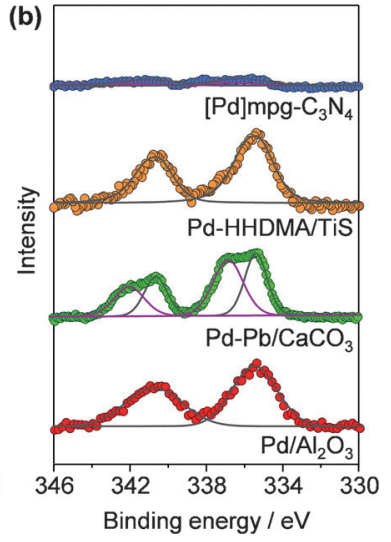

Figure 2. a) $k^{2}$-weighted Fourier transform extended X-ray absorption fine structure spectra (not phase-corrected). b) Pd 3d core level X-ray photoelectron spectroscopy of the catalysts. The circles in (b) represent the experimental data, whereas the gray and violet lines show the fitted $\mathrm{Pd}^{0}$ and $\mathrm{Pd}^{2+}$ components, respectively.

This carbon nitride material was then studied by DFT calculations for the first time to analyze the nature of the isolated $\mathrm{Pd}$ sites incorporated into $\mathrm{mpg}-\mathrm{C}_{3} \mathrm{~N}_{4}$, their stability, and reactivity. The unique features of $\mathrm{mpg}-\mathrm{C}_{3} \mathrm{~N}_{4}$ complicate the calculations as a large rumpling is expected for this kind of two-dimensional materials. In the modeling, special attention was thus paid to the structural landscape, including the $\mathrm{Pd}$ adsorption in "cages", potential intercalation between the graphitic layers, aggregation of $\mathrm{Pd}$, and diffusion. The high complexity observed has prompted us to present only the most remarkable results. DFT calculations on a model surface representing mpg- $\mathrm{C}_{3} \mathrm{~N}_{4}$ revealed that the presence of an atomic distribution of $\mathrm{Pd}$ can be attributed to the function of the $\mathrm{N}$ species in the support, which electrostatically stabilize the Pd species. In fact, the trapping of $\mathrm{Pd}$ in the six-fold cavities is exothermic by $1.5 \mathrm{eV}$ with respect to the gas-phase atomic reference (Figure S1). This strong interaction between the nitrogen atoms on the surface and the metal, coupled with the large number of homogeneously distributed anchoring centers, leads to the stabilization of palladium atoms and appears to be fundamental for the design of a stable singlesite catalyst for hydrogenation reactions. A different support with fully accessible sites (such as alumina) would suffer from rapid agglomeration of the metal (see also Figure $3 \mathrm{c}$ ). Considering that the six-fold cavities are present over the entire mpg- $\mathrm{C}_{3} \mathrm{~N}_{4}$ material with a density of approximately $1 /$ $50 \AA^{2}$, it is possible that during synthesis, parts of the metal phase diffuse between the $\mathrm{C}_{3} \mathrm{~N}_{4}$ layers until a stable, final configuration is reached. This indicates that palladium can also occupy subsurface and deeper positions in the form of an intercalation compound (Figure S2). However, in the resting state, Pd atoms placed in subsurface positions are slightly more stable (see the Supporting Information for a detailed analysis). Considering the specific surface area of mpg- $\mathrm{C}_{3} \mathrm{~N}_{4}$, the surface density of the six-fold cavities in a fully uniform layer, the total palladium loading, and assuming that all palladium is located at the surface, we could estimate that 8 $10 \%$ of all surface six-fold cavities are occupied by palladium (see the Supporting Information for a detailed analysis). This 
is only an estimate as Pd can also be distributed deep in the graphitic layers, reducing the effective fraction of "surface cage" occupation. Comparatively, in a $10 \mathrm{~nm}$ nanoparticle, $6 \%$ of the Pd atoms would be located on the surface. ${ }^{[8 b]}$ From a thermodynamic point of view, the aggregation of $\mathrm{Pd}$ atoms to form dimers, trimers, or larger clusters is not favored (Figure S3). Furthermore, considering the low palladium loading and quite large number of nesting positions, entropic contributions dominate, clarifying the stability of the atomic sites. Only at high Pd contents, the six-fold cavities are saturated with atomic species, and metal agglomeration starts. This explains, for instance, the presence of nanoparticles of approximately $3 \mathrm{~nm}$ when 20 times higher palladium loadings were employed and the same preparation procedure was followed. ${ }^{[6 c]}$

The structure of [Pd]mpg- $\mathrm{C}_{3} \mathrm{~N}_{4}$ can be compared with that of three benchmark catalysts that are commercially available and widely utilized in industry: ligand-modified $\mathrm{Pd}$ HHDMA/TiS (HHDMA = hexadecyl-2-hydroxyethyl-dimethylammonium dihydrogen phosphate), Lindlar-type $\mathrm{Pd}-\mathrm{Pb} /$ $\mathrm{CaCO}_{3}$, and $\mathrm{Pd} / \mathrm{Al}_{2} \mathrm{O}_{3}$ (Figure 1 and Table 1). Although $[\mathrm{Pd}] \mathrm{mpg}-\mathrm{C}_{3} \mathrm{~N}_{4}$ has the same metal loading as Pd-HHDMA/ TiS, the latter material contains particles with an average diameter of approximately $8 \mathrm{~nm}$ deposited on titanium silicate $\left(S_{\mathrm{BET}}=229 \mathrm{~m}^{2} \mathrm{~g}^{-1}\right)$. Not all of the surface atoms in the HHDMA-modified nanoparticles take part in the reaction: In fact, the ligand blocks about $75 \%$ of the metal surface, leading to ensembles with a size of approximately $0.8 \mathrm{~nm} .^{[2 \mathrm{f}]}$ The reference $\mathrm{Pd}-\mathrm{Pb} / \mathrm{CaCO}_{3}$ catalyst contains significantly more palladium as well as lead $(5 \mathrm{wt} \% \mathrm{Pd}$, $3 \mathrm{wt} \% \mathrm{~Pb}$, surface $\mathrm{Pd} / \mathrm{Pb}$ ratio $=1.3)$. The catalyst exhibits a total area of $10 \mathrm{~m}^{2} \mathrm{~g}^{-1}$ and a pore volume of $0.03 \mathrm{~cm}^{3} \mathrm{~g}^{-1}$. The $\mathrm{Pd}-\mathrm{Pb}$ nanoparticles are homogeneously distributed over $\mathrm{CaCO}_{3}$ and have an average diameter of $14 \mathrm{~nm}$ (metal dispersion: $6-8 \%$ ). Similar to the role of HHDMA, $\mathrm{Pb}$ isolates the $\mathrm{Pd}$ sites, leading to ensembles with a size of approximately $1 \mathrm{~nm}$. Finally, $\mathrm{Pd} / \mathrm{A}_{2} \mathrm{O}_{3}$ contains uniformly sized bare palladium nanoparticles with average diameters of about $3 \mathrm{~nm}$. The particles are deposited on porous alumina $\left(V_{\text {pore }}=0.64 \mathrm{~cm}^{3} \mathrm{~g}^{-1}\right)$ with a total surface area of $170 \mathrm{~m}^{2} \mathrm{~g}^{-1} . \mathrm{In}$ all these cases, XAS analyses detected only Pd-O (1.8-2.0 $\AA$ ) and $\mathrm{Pd}-\mathrm{Pd}(2.5-2.7 \AA$ ) bonds (Figure $2 \mathrm{a}$ and Figure $\mathrm{S} 4)$.

To confirm the various degrees of metal dispersion in the four samples, $\mathrm{CO}$ chemisorption studies were conducted. During pulse chemisorption, [Pd]mpg- $\mathrm{C}_{3} \mathrm{~N}_{4}$ showed no adsorption of the probe molecules, whereas the other reference materials showed a quantifiable $\mathrm{CO}$ uptake, in accordance with the degrees of dispersion determined by microscopy (Table 1). The absence of $\mathrm{CO}$ uptake over $[\mathrm{Pd}] \mathrm{mpg}-\mathrm{C}_{3} \mathrm{~N}_{4}$ was confirmed by infrared spectroscopy in transmission mode (Figure S5). This result indicates that individual Pd atoms behave differently than those in a conventional nanoparticle, in line with the recent work by Schlögl and co-workers. ${ }^{[8 c]}$ As the $\mathrm{Pd}$ atoms lay below the plane formed by the six-fold cavities, the cage is enriched in electron density, and this prevents carbon monoxide from getting close to the palladium atoms. This shield is very effective, and CO cannot adsorb (the DFT-calculated adsorption energy is largely endothermic, by $0.86 \mathrm{eV}$ ). Further insights into the material structure were obtained by X-ray photoelectron spectroscopy (Figure $2 \mathrm{~b}$ ). A single Pd $3 \mathrm{~d}_{5 / 2}$ binding energy of $335.5 \mathrm{eV}$, corresponding to $\mathrm{Pd}^{0}$, was observed for $\mathrm{Pd}-$ HHDMA/TiS and $\mathrm{Pd} / \mathrm{Al}_{2} \mathrm{O}_{3}$. The signal is broader in the case of $\mathrm{Pd}-\mathrm{Pb} / \mathrm{CaCO}_{3}$ owing to the presence of $\mathrm{Pd}^{2+}-\mathrm{Pb}$ species. In contrast, the XPS signal was not very intense for $[\mathrm{Pd}] \mathrm{mpg}-\mathrm{C}_{3} \mathrm{~N}_{4}$, likely because the detection of isolated $\mathrm{Pd}$ species at low concentrations is below the detection limit of the instrument. Sputtering with an $\mathrm{Ar}^{+}$beam was conducted to remove surface layers in a stepwise fashion to gain access to the bulk composition of the material. In this case, an increase in the palladium content with depth could be observed (Figure S6), from a Pd content of 0.15 at. \% in the surface to 0.5 at. \% in the bulk. This finding confirms that part of the palladium phase is homogeneously incorporated between the graphitic layers of the support, in agreement with the DFT calculations. Furthermore, during sputtering, the $\mathrm{Pd} 3 \mathrm{~d}_{5 / 2}$ peak is slightly shifted to higher binding energies (336.4 eV). This could be due to quantum effects that appear for "particles" smaller than $2 \mathrm{~nm}$, although a $\mathrm{Pd}^{2+}$ contribution cannot be excluded.

To illustrate the benefits of single-site catalysis, the [Pd]mpg- $\mathrm{C}_{3} \mathrm{~N}_{4}$ catalyst was used for the hydrogenation of 1hexyne (Figure $3 \mathrm{a}$ ), a reference compound that well represents typical alkynes employed for the manufacture of highadded-value compounds in the fine chemical and pharmaceutical industries. The rate of reaction at $303 \mathrm{~K}$ and 1 bar is three orders of magnitude larger than that of other catalytic systems (based on $\mathrm{Ag}, \mathrm{Au}, \mathrm{CeO}_{2}$ ). ${ }^{[9]}$ This demonstrates that the single-site catalyst can be applied in the manufacture of fine chemicals and pharmaceuticals. Furthermore, below $363 \mathrm{~K}$ and 2 bar, the selectivity to 1-hexene is nearly $100 \%$, pointing to the resistance of the material towards the formation of $\beta$-hydrides. These results can be appreciated when they are compared to the performance of benchmark Pd-based hydrogenation catalysts (see also Figure S7). For the hydrogenation of 1-hexyne at $343 \mathrm{~K}$ and 5 bar, [Pd]mpg$\mathrm{C}_{3} \mathrm{~N}_{4}$ and Pd-HHDMA/TiS display similar activities $(1.41 \times$ $10^{3}$ and $1.38 \times 10^{3}$ mol $_{\text {product }}$ mol $_{\mathrm{Pd}^{-1}} \mathrm{~h}^{-1}$, respectively) and high olefin selectivities $(90 \%)$. In contrast, while the Lindlar catalyst shows an excellent degree of selectivity to the terminal alkene $(90 \%)$, its activity $(0.34 \times$ $\left.10^{3} \mathrm{~mol}_{\text {product }} \mathrm{mol}_{\mathrm{Pd}}{ }^{-1} \mathrm{~h}^{-1}\right)$ is much lower in spite of the high $\mathrm{Pd}$ content (5 wt \%). The non-promoted $\mathrm{Pd} / \mathrm{Al}_{2} \mathrm{O}_{3}$ catalyst is fairly active $\left(0.96 \times 10^{3} \mathrm{~mol}_{\text {product }} \mathrm{mol}_{\mathrm{Pd}}{ }^{-1} \mathrm{~h}^{-1}\right)$, but poorly selective to the corresponding olefin $(69 \%)$, yielding various isomers and the alkane as side products. The resistance of $[\mathrm{Pd}] \mathrm{mpg}-\mathrm{C}_{3} \mathrm{~N}_{4}$ towards metal loss (a possible deactivation pathway for single-site catalysts) was assessed in a catalytic run at $343 \mathrm{~K}$ and 5 bar for $20 \mathrm{~h}$ (Figure $3 \mathrm{~b}$ ). No decrease in alkyne conversion and alkene selectivity could be observed, pointing to the absence of any metal aggregates (Figure $3 \mathrm{c}$ ). This catalytic performance was confirmed for the hydrogenation of 2-methyl-3-butyn-2-ol to 2-methyl-3-buten-2-ol and 3-hexyne to cis-3-hexene, demonstrating the chemo- and stereoselectivity of the catalyst in alkyne hydrogenation (cis/ trans ratio $>20$ ), and finally applied to the hydrogenation of nitrobenzene to aniline (Figure S8; see the Supporting Information for the reaction conditions). 

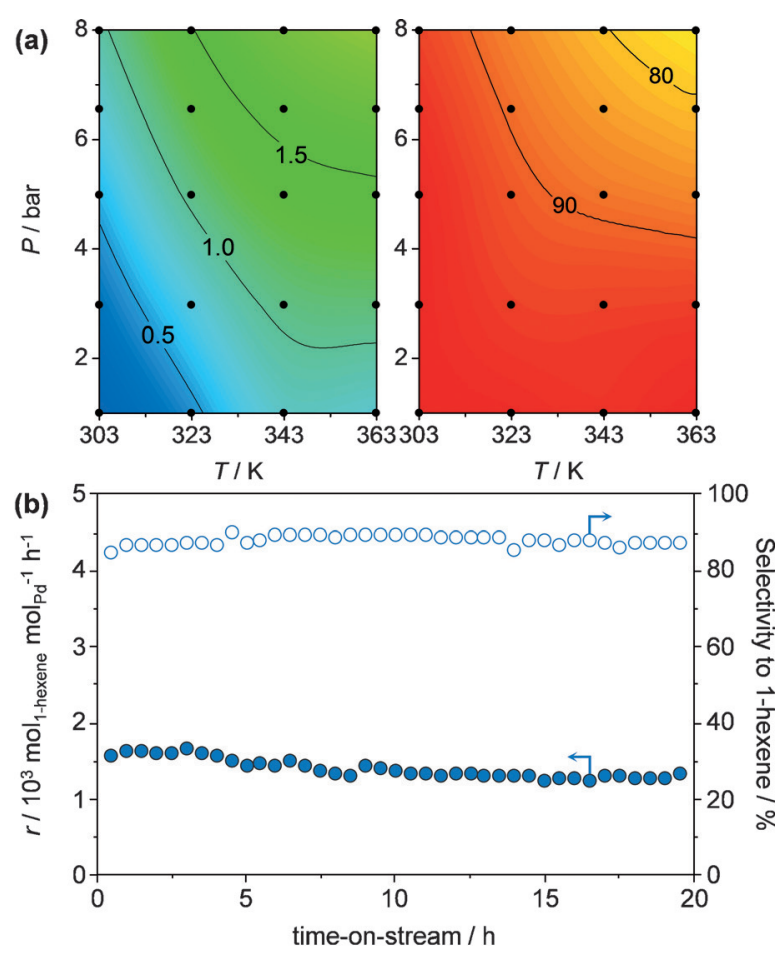

(c)

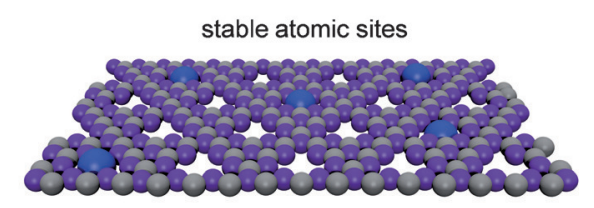

aggregation
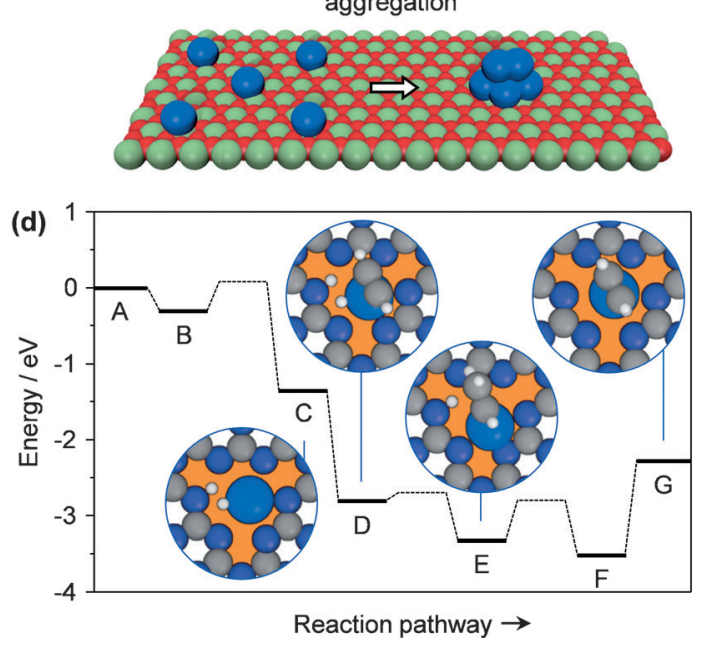

Figure 3. a) Reaction rates (in $10^{3}$ mol $_{\text {product }}$ mol $_{\mathrm{Pd}^{-1}} \mathrm{~h}^{-1}$; left), selectivity to 1 -hexene (in \%; right), and b) stability over the course of $20 \mathrm{~h}$ at $343 \mathrm{~K}$ and 5 bar during the hydrogenation of 1 -hexyne over [Pd]mpg$\mathrm{C}_{3} \mathrm{~N}_{4}$. The contour maps in (a) were obtained through spline interpolation of the experimental points shown as black dots. c) Representation showing isolated Pd species on carbon nitride (top) and alumina (bottom). Whereas the atoms on the alumina support are unstable and tend to aggregate, forming a Pd cluster, this does not occur with mpg- $\mathrm{C}_{3} \mathrm{~N}_{4}$. d) Energy profile for the hydrogenation of acetylene over a single $\mathrm{Pd}$ atom. Al green, $\mathrm{C}$ dark gray, $\mathrm{H}$ white, $\mathrm{N}$ purple, $\mathrm{O}$ red, Pd blue.
To be able to rationalize the outstanding hydrogenation performance of [Pd]mpg- $\mathrm{C}_{3} \mathrm{~N}_{4}$, we conducted DFT calculations using acetylene as a surrogate alkyne (Figure $3 \mathrm{~d}$ ). The reasons for the choice of a smaller alkyne are the following: 1) Several reaction paths were investigated in this work, with and without considering the promoting role of the support, complicating the calculations; 2) the large rumpling of the carbon nitride, together with the conformational flexibility of larger alkynes, renders the proper location of the transition states difficult; and, most importantly, 3) the adsorption energy of acetylene and 1-hexyne were found to be within a few meV. Therefore, the results for acetylene can be easily transferred to more complex compounds. The reaction closely follows the pathway of homogeneous systems ${ }^{[10 a]}$ and takes place on the isolated $\mathrm{Pd}$ species in the six-fold nests (alternative configurations are described in the Supporting Information). On the isolated $\mathrm{Pd}$ sites, the hydrogenation occurs by the coordination of molecular hydrogen by $-0.30 \mathrm{eV}$ (B), which undergoes heterolytic dissociation (C), leaving one of the hydrogen atoms bound to an $\mathrm{N}$ atom in the lattice and the second one on a Pd atom. Thus, there is an active participation of the support, which fulfills the role that ligands adopt in homogeneous catalysis. The $\mathrm{N}$ atom thus becomes positively polarized and the aromaticity of the heptazine core is partially lost. As a consequence, the $\mathrm{Pd}$ atom is partially pulled out of the cavity. This step is almost barrierfree with respect to the gas-phase molecule when the zeropoint energy is considered and exothermic by $-1.34 \mathrm{eV}$ with respect to the gas-phase reactants. The acetylenic compound can be adsorbed in a highly activated form (H-C-C angle $=$ $153^{\circ}$ ) with release of $0.5 \mathrm{eV}$ (D). The $\mathrm{H}$ atom is transferred to the organic moiety, leading to $\mathrm{C}_{2} \mathrm{H}_{3}(\mathrm{E})$ and $\mathrm{C}_{2} \mathrm{H}_{4}(\mathrm{~F})$. The energy barrier of this last step is $0.5 \mathrm{eV}$. Afterwards, the alkene product desorbs $(\mathrm{G})$. Therefore, the coordination of the product without activation, ${ }^{[10 \mathrm{~b}]}$ preventing over-hydrogenation and oligomerization, and the absence of electronrich palladium centers as determined by Bader analysis ${ }^{[10 c]}$ are key for the high selectivity of [Pd]mpg- $\mathrm{C}_{3} \mathrm{~N}_{4}$.

In conclusion, we have shown that isolated $\mathrm{Pd}$ atoms can be confined into the six-fold cavities of mpg- $\mathrm{C}_{3} \mathrm{~N}_{4}$ in a stable manner, enabling the design of a single-site Pd catalyst for the flow hydrogenation of alkynes and nitroarenes. The material surpasses the activity of conventional heterogeneous catalysts based on nanoparticles, while maintaining an outstanding degree of product selectivity $(>90 \%)$ and circumventing typical instabilities that occur with the miniaturization of the ensemble size. The performance was rationalized at the molecular level by DFT calculations, showing that the high activity and selectivity is due to the facile hydrogen activation and alkyne adsorption on the atomically dispersed Pd sites. The support simulates enzymatic environments, such as those in porphyrins, and simultaneously acts as a spacer, distributing the active sites almost homogeneously, and as a ligand, both inhibiting the adsorption of potential poisons $(\mathrm{CO})$ and promoting the activation of $\mathrm{H}_{2}$, which converts the metal into the active form. We believe that the proof-of-concept study based on the $[\mathrm{Pd}] \mathrm{mpg}-\mathrm{C}_{3} \mathrm{~N}_{4}$ catalyst can be extrapolated for the design of new heterogeneous single-site catalysts for 
a variety of reactions, including continuous hydrogenations, $\mathrm{C}-\mathrm{C}$ coupling reactions, and beyond.

\section{Experimental Section}

Details on the catalyst preparation, characterization, testing, and theoretical calculations are given in the Supporting Information. Mesoporous polymeric graphitic carbon nitride was prepared by thermally induced self-condensation of cyanamide using colloidal silica as the template. ${ }^{[6]}$ The material was dispersed in deionized water and mixed with an aqueous solution of $\mathrm{PdCl}_{2}$ and $\mathrm{NaCl}$. The resulting suspension was kept at room temperature for $1 \mathrm{~h}$ under vigorous stirring in an ultrasound bath. After the addition of $\mathrm{NaBH}_{4}$, the slurry was filtered and dried, yielding $[\mathrm{Pd}] \mathrm{mpg}-\mathrm{C}_{3} \mathrm{~N}_{4}$. The three-phase hydrogenation of 1-hexyne was studied in a continuous-flow threephase reactor ${ }^{[2 \mathrm{f}, \mathrm{g}, 9]}$ under the following conditions: catalyst mass $W_{\text {cat }}=0.1 \mathrm{~g}$ (particle size : $0.2-0.4 \mathrm{~mm}$ ), temperature $T=303-363 \mathrm{~K}$, total pressure $P=1-8 \mathrm{bar}$, hydrogen flow rate $F_{\mathrm{G}}=24 \mathrm{~cm}^{3} \mathrm{~min}^{-1}$, and liquid flow rate $F_{\mathrm{L}}=1 \mathrm{~cm}^{3} \mathrm{~min}^{-1}$. Density functional theory calculations conducted with the Vienna ab initio simulation package ${ }^{[11]}$ enabled the modelling of the structure of the material and its reactivity.

\section{Acknowledgements}

Dr. Frank Krumeich (ETH Zurich) and Dr. Roland Hauert (EMPA Dübendorf) are acknowledged for the STEM and XPS analyses, respectively. Delft Solids Solutions B.V. is thanked for conducting $\mathrm{CO}$ chemisorption analyses. Financial support from the ETH Zurich, the Spanish Ministerio de Economía y Competitividad (CTQ2012-33826), BSC-CNS, and the ICIQ Foundation is also acknowledged.

Keywords: carbon nitride $\cdot$ flow chemistry $\cdot$ palladium . selective hydrogenation $\cdot$ single-site catalysis

How to cite: Angew. Chem. Int. Ed. 2015, 54, 11265-11269 Angew. Chem. 2015, 127, 11417-11422

[1] R. A. Sheldon, H. van Bekkum, Fine Chemicals through Heterogeneous Catalysis, Wiley-VCH, Weinheim, 2001, p. 351.

[2] a) J. A. Anderson, J. Mellor, R. P. K. Wells, J. Catal. 2008, 261, 208; b) D. Teschner, J. Borsodi, A. Wootsch, Z. Révay, M. Hävecker, A. Knop-Gericke, S. D. Jackson, R. Schlögl, Science 2008, 320, 261; c) M. Armbrüster, K. Kovnir, M. Behrens, D Teschner, Y. Grin, R. Schlögl, J. Am. Chem. Soc. 2010, 132, 14745; d) M. García-Mota, B. Bridier, J. Pérez-Ramírez, N. López, J. Catal. 2010, 273, 92; e) P. T. Witte, P. H. Berben, D.
Vogt, J. W. Geus, Top. Catal. 2012, 55, 505; f) G. Vilé, N. AlmoraBarrios, S. Mitchell, N. López, J. Pérez-Ramírez, Chem. Eur. J. 2014, 20, 5926; g) G. Vilé, N. Almora-Barrios, N. López, J. PérezRamírez, ACS Catal. 2015, 5, 3767.

[3] a) A. Borodziński, Catal. Lett. 2001, 71, 169; b) N. Semagina, L. Kiwi-Minsker, Catal. Rev. Sci. Eng. 2009, 51, 147.

[4] a) J. M. Thomas, R. Raya, D. W. Lewis, Angew. Chem. Int. Ed. 2005, 44, 6456; Angew. Chem. 2005, 117, 6614; b) J. M. Thomas, Design and Applications of Single-Site Heterogeneous Catalysis, Imperial College Press, London, 2012, p. 3; c) J. Pérez-Ramírez, Angew. Chem. Int. Ed. 2013, 52, 9892; Angew. Chem. 2013, 125, 10076.

[5] a) G. Kyriakou, M. B. Boucher, A. D. Jewell, E. A. Lewis, T. J. Lawton, A. E. Baber, H. L. Tierney, M. Flytzani-Stephanopolous, E. C. H. Sykes, Science 2012, 335, 1209; b) S. F. J. Hackett, R. M. Brydson, M. H. Gass, I. Harvey, A. D. Newman, K. Wilson, A. F. Lee, Angew. Chem. Int. Ed. 2007, 46, 8593; Angew. Chem. 2007, 119, 8747; c) X. Yang, A. Wang, B. Qiao, J. Li, J. Liu, T. Zhang, Acc. Chem. Res. 2013, 46, 1740; d) E. J. Peterson, A. T. DeLaRiva, S. Lin, R. S. Johnson, H. Guo, J. T. Miller, J. H. Kwak, C. H. F. Peden, B. Kiefer, L. F. Allard, F. H. Ribeiro, A. K. Datye, Nat. Commun. 2014, 5, 4885; e) H. Wei, X. Liu, A. Wang, L. Zhang, B. Qiao, X. Yang, Y. Huang, J. Miao, T. Zhang, Nat. Commun. 2014, 5, 5634.

[6] a) F. Goettmann, A. Fischer, M. Antonietti, A. Thomas, Angew. Chem. Int. Ed. 2006, 45, 4467; Angew. Chem. 2006, 118, 4579; b) A. Thomas, A. Fisher, F. Göttmann, M. Antonietti, J.-O. Müller, R. Schlögl, J. M. Carlsson, J. Mater. Chem. 2008, 18, 4893 ; c) Y. Li, X. Xu, P. Zhang, Y. Gong, H. Li, Y. Wang, RSC Adv. 2013, 3, 10973.

[7] Y. Wang, X. Wang, M. Antonietti, Angew. Chem. Int. Ed. 2012, 51, 68; Angew. Chem. 2012, 124, 70.

[8] a) M. W. Tew, H. Emerich, J. A. van Bokhoven, J. Phys. Chem. C 2011, 115, 8457; b) M. Mavrikakis, P. Stoltze, J. K. Nørskov, Catal. Lett. 2000, 64, 101; c) R. Arrigo, M. E. Schuster, Z. Xie, Y. Yi, G. Wowsnick, L. L. Sun, K. E. Hermann, M. Friedrich, P. Kast, M. Hävecker, A. Knop-Gericke, R. Schlögl, ACS Catal. 2015, 5, 2740.

[9] a) G. Vilé, J. Pérez-Ramírez, Nanoscale 2014, 6, 13476; b) G. Vilé, S. Wrabetz, L. Floryan, M. E. Schuster, F. Girgsdies, D. Teschner, J. Pérez-Ramírez, ChemCatChem 2014, 6, 1928.

[10] a) J. López-Serrano, S. B. Duckett, A. Lledós, J. Am. Chem. Soc. 2006, 128, 9596; b) F. Studt, F. Abild-Pedersen, T. Bligaard, R. Z. Sørensen, C. H. Christensen, J. K. Nørskov, Science 2008, 320, 1320 ; c) S. Abbet, A. Sanchez, U. Heiz, W.-D. Schneider, A. M. Ferrari, G. Pacchioni, N. Rösch, J. Am. Chem. Soc. 2000, 122, 3453.

[11] G. Kresse, J. Hafner, Phys. Rev. B 1993, 47, 558.

Received: June 3, 2015

Published online: July 31, 2015 